\title{
Arquitectura y prospectividad en los fascismos: Ciencia ficción como punto de partida, utopía como futuro, distopía como destino
}

\author{
Antonio SÁNCHEZ DOMÍNGUEZ \\ Departamento de Filosofía Teorética \\ Universidad Complutense de Madrid \\ antoniosd88@gmail.com
}

Fecha de recepción: 29 de septiembre de 2011

Fecha de modificación: 26 de noviembre de 2011

Fecha de aceptación: 28 de noviembre de 2011

\section{Resumen}

La ciencia ficción y la arquitectura siempre han estado unidas. El anhelo oculto de muchos arquitectos ha sido diseñar ciudades de ensueño. Hitler, siguiendo la estela de otros regímenes imperiales, y en una suerte de pacto fáustico, les concedió a sus arquitectos, en concreto a Albert Speer, la posibilidad de diseñar su utopía. Y para ello, la ciencia ficción y tecnologías casi inexistentes eran el punto de partida. Punto de partida y nóvum que pronto revelará la doble cara de esa moneda que es la técnica.

Palabras clave: distopía, prospectividad, técnica, ontología negativa, nóvum, ruinas.

Title: Arquitecture and prospectivity in the fascist age

\section{Abstract}

Science fiction and architecture have always been linked. The hidden desire of many architects has been to design dream cities. Hitler, in the wake of other imperial regimes, and in a sort of Faustian agreement, gave his architects, notably Albert Speer, the possibility of designing his utopy. To that end science fiction and almost non-existent technologies were the starting point. Starting point and "nóvum" that will soon reveal as the both sides of this coin in which technique consist of.

Keywords: dystopia, prospectivity, technique, negative ontology, nóvum, ruins.

\section{Índice}

1. Introducción

2. Albert Speer y la construcción de Germania como nóvum

3. La necesidad de un nuevo concepto de tiempo para la arquitectura y para la ciencia ficción: la preeminencia del futuro

4. La "filosofía de las ruinas" o la "ontología de lo post-apocalíptico"

5. Conclusiones 


\section{Introducción}

Desde los edificios y la ciudad en el clásico de Fritz Lang Metrópolis, a la ya manida estética oscura de la urbe en Blade Runner, la arquitectura, la ciudad y la ciencia ficción han ido de la mano en proponer siempre paradigmas fácilmente conciliables con nuestra forma de entender el mundo. Pero lo que este artículo pretende es ver cómo en la historia del siglo $\mathrm{XX}$, en un periodo concreto, la delgada línea que separa la realidad de la ciencia ficción se desdibujó mediante un pacto faústico entre un dictador y un joven arquitecto. La idea: hacer del presente el futuro; la herramienta: el pasado, el nóvum y la nada.

En el presente artículo hemos pretendido mostrar, de una manera breve, como tanto la ciencia ficción como la arquitectura recurren pues a una forma determinada de prospectividad, en la que los elementos sociales y el tiempo histórico se entremezclan para construir así su objeto central, en un caso una obra de literatura y en otro caso un edificio.

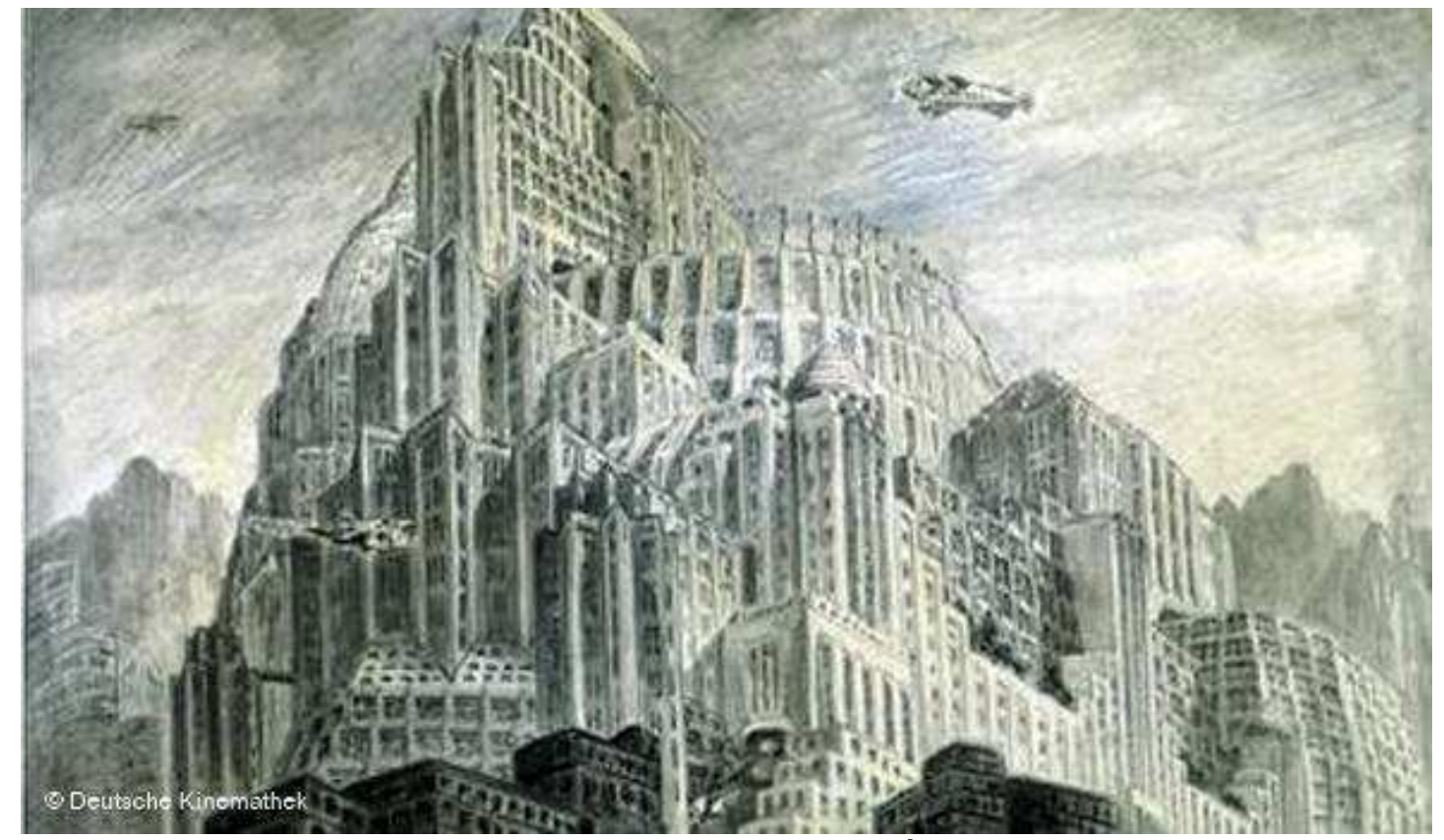

Figura 1. Dibujo de Metrópolis.

La elección del título intenta, tal y como se ha de esperar de un título, mostrar en pocas palabras las consideraciones que realizamos acerca de la visión fascista de la arquitectura y su relación, en concreto, con uno de los periodos más convulsos de la historia europea, el auge y el fin de los fascismos. Pero además, el artículo pretende tratar a esa ciudad fascista como un lugar en el que lo prospectivo se juega en su máximo exponente. 


\section{Albert Speer y la construcción de Germania como nóvum}

Ríos de tinta son los que han corrido en torno a la figura tanto ambigua como estimulante de Albert Speer, y no es nuestra intención centrarnos aquí y tratar una vez más su polémica relación con el nazismo o hacer un balance de su obra, sino más bien realizar un pequeño acercamiento a la idea que en él se proyecta sobre lo que debiera de ser la arquitectura y su labor en un mundo en el que el futuro se consideraba alcanzado y la ciencia ficción pues, el punto de partida. La obra de Speer forzó la ingeniería de su tiempo hasta límites insospechados, requiriendo una cantidad de recursos que Hitler no dudaba, la mayoría de las veces, en otorgar a Speer.

¿Cuál es la relación con la ficción prospectiva? Para ello vamos a buscar una definición de nóvum: "referido al motivo que constituye la base de desarrollo de cualquier obra de ficción prospectiva [...], que deberá ser proyectivo, pero no sobrenatural" (Moreno 2010: $459)^{1}$. Con esta definición es fácil anticipar lo que viene y su relación con ciertos tipos de arquitectura.

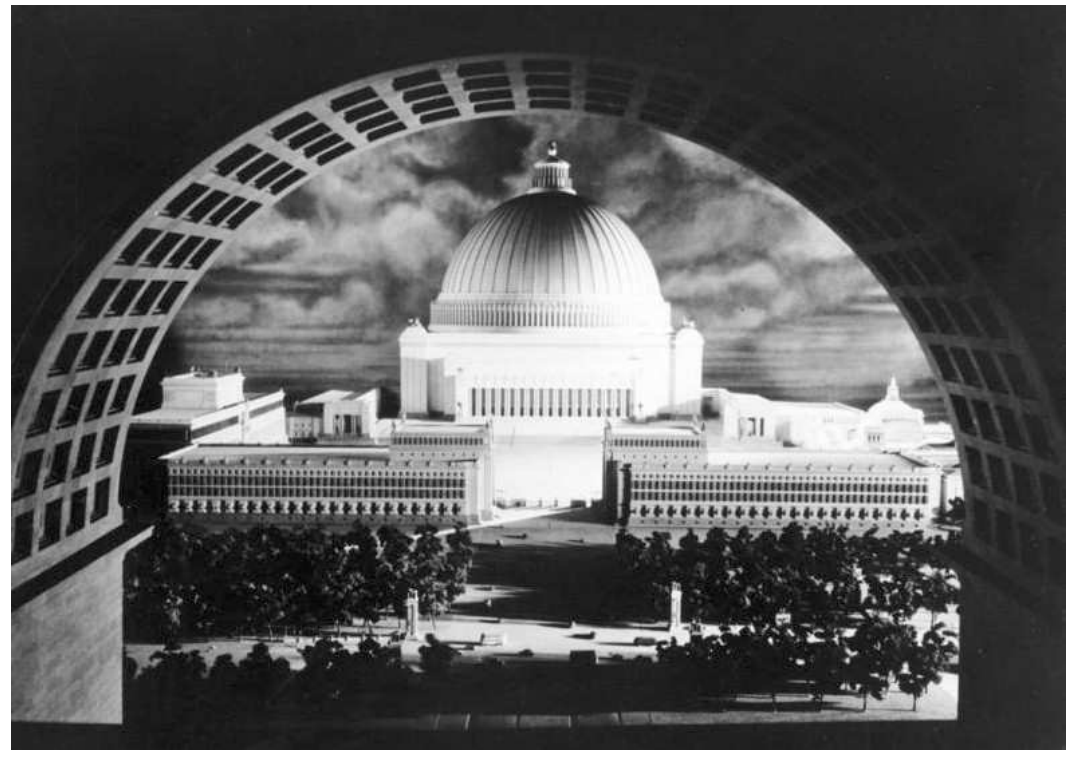

Figura 2. Maqueta de Germania.

La creación de Germania, que sustituiría a la vieja Berlín, era parte fundamental en el desarrollo de la utopía totalitaria (figura 2). Germania no era un proyecto para este siglo. Era un proyecto que tendría que definir y servir de centro neurálgico del mundo de los próximos diez siglos. Esa visión orientada al futuro, que en cierto modo siempre forma parte de la arquitectura, se elevaba aquí a su máximo exponente. $Y$ es que los totalitarismos albergan en su seno, si atendemos a las definiciones historiográficas que se dan, un intento

${ }^{1}$ Para el análisis de la constitución y realización a través de la obra del concepto de nóvum, vid. Moreno (2010: 184-191). 
de conjugar paradigmas claramente conservadores con ideas que en muchos casos parten de lo que podríamos entender como nóvum. Ese acercamiento a la ciencia que se da desde una filosofía vitalista desemboca en que nada sea tomado como estupidez o fantasía, que el nóvum tenga plausibilidad, y que la medida de su consistencia como proyecto sea siempre la posibilidad de engrandecer esa corporación que es el Reich.

La actitud vivencial propia de esta arquitectura pretendía al mismo tiempo eliminar ese espacio de alienación que es la urbe, dotándola de un sentido metafísico penetrante y simbólico, una suerte de integración del ciudadano en su Zeitgeist, hacer al hombre importante en su existencia y autonomía pero a la vez encajarlo siempre en la corriente que era la masa.

La nueva ciudad de Hitler y Speer, Germania, tenía que estar diseñada para satisfacer ese modelo corporativo, utópico y vitalista que estaba en la base de la "filosofía" del Reich. El nuevo "destino manifiesto" alemán y la grandilocuencia del neoclasicismo desnudo eran el suelo de ese historicismo que pretendía purificar las raíces de la sociedad alemana: "Durante los años cruciales de mi vida me puse al servicio de la técnica, deslumbrado por sus posibilidades. Al final ya no me queda más que escepticismo" (Speer 1969: 930).

Estas palabras, localizadas al final de las memorias del arquitecto Albert Speer, simbolizan ese deslumbramiento propio en el hombre ante las posibilidades de la técnica, así como el escepticismo que acompaña a esas posibilidades tras ver los frutos y fracasos de la misma; esa doble cara de la moneda, ese universo tantas veces caracterizado en la ciencia ficción, donde deslumbrantes mundos tienen a la vez esa cara oculta de oscuridad. La época en la que Speer construye sus edificios, principalmente en lo que dura el tercer Reich, se entrecruza con el nacimiento y duración de la edad dorada de la ciencia ficción (normalmente acotada entre 1938 y 1950). Esa ciencia ficción que en sus obras, sobre todo postholocausto, empieza a desdibujar esa misma doble cara de la moneda, la cara brillante y la cara gris y amarga.

Esta catástrofe ha puesto de manifiesto la vulnerabilidad del sistema de la civilización moderna, edificado a través de los siglos. Ahora sabemos que no vivimos en un edificio a prueba de terremotos. El complicado aparato del mundo moderno puede, mediante impulsos negativos que se incrementan mutuamente, descomponerse de forma irremisible. Ninguna voluntad humana podría detener esta evolución si el automatismo del progreso diera otro paso en su marcha hacia la despersonalización del hombre y lo privara cada vez más de la responsabilidad de sus propios actos. (Speer 1969: 930) 


\section{La necesidad de un nuevo concepto de tiempo para la arquitectura y para la ciencia ficción: la preeminencia del futuro}

La realidad gestada en la época de entreguerras empezó a reclamar conceptos de tiempo unidos a ese carácter pesimista ${ }^{2}$ y de tonalidades existenciales tan en boga. Ese nuevo concepto de tiempo satisfacía las exigencias mínimas que hemos pergeñado para el concepto de arquitectura prospectiva. $Y$ esa idea de tiempo vino de la mano de Martin Heidegger, que en una polémica con Husserl construirá su propia concepción del tiempo, que marcará una época y transmitirá bien las ideas que nos interesan de cara a este artículo.

Desde la época de Aristóteles se venía arrastrando una concepción del tiempo basada en una serie de "ahoras", lo que será denominado por Heidegger "concepción vulgar del tiempo". Husserl llamará a esta serie de ahoras "tiempo objetivo", pues constituye "la forma fija en la cual nos salen al encuentro todos los objetos localizables en el tiempo" (Held 2009: 10). Es frente a esa noción de tiempo objetivo que Husserl contrapone la "conciencia interna del tiempo", o, como aparecerá en los manuscritos de los años 30, el "presente viviente", que Heidegger modificará a su manera y le dará el tono que aquí nos interesa. Como afirma Klaus Held:

Husserl y Heidegger coinciden objetiva, aunque no terminológicamente, en el siguiente punto: Nuestra concepción familiar como serie de ahoras debe aclararse como comprensión derivada del tiempo propio. [...] No debe limitarse a iluminar los rasgos del tiempo propio, sino además como éste condiciona al tiempo impropio o lo posibilita. (Held 2009: 14)

Heidegger hará explícito el planteamiento dando a entender, directamente, que existe una primacía del futuro: ¿Qué significa esto? Pues básicamente una cosa, y es que Heidegger está cambiando, en ese concepto de tiempo, la primacía del presente por la primacía del futuro.

Heidegger define el Dasein (ser-ahí / estar-ahí) como una entidad curiosa, de preocupación preeminentemente por el futuro, y que se entiende a sí mismo desde su arrojo, es decir, desde anticipaciones explícitas en mayor o menor grado.

No hay interpretación sin una anticipación comprendedora. La idea aquí es que en una interpretación nos encontramos dirigidos por expectativas de intelección. Si entendemos con Heidegger que existe una primacía temporal en el futuro, que uno siempre está proyectado

2 Como caso paradigmático destaca La decadencia de Occidente, de Oswald Spengler. 
hacia el mismo, los paralelismos con la noción de prospectivo son evidentes.

"No me quedo sólo con la idea de futuro, sino también con la de exploración del subsuelo y con la de descubrir enfermedades latentes o incipientes" (Moreno 2010: 122). Esta afirmación, recogida por el autor Fernando Ángel Moreno al respecto de "lo prospectivo", es adoptada por Heidegger al respecto de la existencia misma del Dasein.

Partimos de que la temporalidad está anclada en una referencia al sí mismo. La prospectividad va a quedar "secuestrada" y motivada por la relación entre la inextirpable reflexividad y la preeminencia del futuro, y en la conjugación de ambas produce sus obras.

Ramón Rodríguez lo explica de la siguiente manera: "el sí mismo no desaparece en la salida, sino que se mantiene y retorna, los rasgos descriptivos de la temporalidad, venir a sí (auf-sichzukommen), retornar a sí (zurück zu sich kommen) y mantenerse en (sichaufhalten bei) contienen todos ellos esa referencia a un sí mismo" (Rodríguez 2002: 70).

Como decía Derrida, "De Parménides a Husserl, el privilegio del presente jamás ha sido cuestionado" (Derrida 1968: 4). Pero aquí, entre Husserl y Heidegger, a ese presente se le dan unas nuevas connotaciones, y sobre todo en Heidegger, tal y como aclara Ramón Rodríguez, ese 'sí mismo' en el presente está siempre proyectado a lo otro.

Entendido así, lo que hace una obra prospectiva es explicitar esta conexión, el salir de sí mismo y retornar cambiado, el seguir en el no seguir. A fortiori, en el caso de la obra literaria y prospectiva, el nóvum es una lanzadera a la otredad, y esa otredad tiende a venir cifrada en forma de un futuro plausible, dejando de nuevo explicitada la preeminencia del futuro.

La arquitectura y la ciudad funcionan en su seno de una manera similar, pero la asimilación del nóvum por parte de la arquitectura totalitaria iguala a esta con la literatura prospectiva.

La nueva concepción temporal, que da preeminencia al futuro, satisface las necesidades de una época que necesita huir de la dureza de esa etapa de entreguerras y encaja en esa visión vivencial y heroica de la vida. Además es fácil emparentarla, por medio de un hábil manipulador, con temas como utopía o destino, pero también con términos como distopía.

\section{La "filosofía de las ruinas" o la "ontología de lo post- apocalíptico"}

"A Hitler le gustaba explicar que edificaba para legar a la posteridad el espíritu de su tiempo" (Speer 1969: 102). Con esta frase y con ese "espíritu" Hitler consagraba su "filosofía" constructora a ese futuro. Hitler estaba convencido de que la historia de los pueblos está 
salpicada por diferentes periodos, algunos de declive y otros de alza. En esos momentos de "flaqueza histórica" siempre se podían usar los monumentos para apelar a la grandeza del espíritu nacional. "Así, las obras del imperio Romano permitían a Mussolini remitirse al espíritu heroico de Roma cuando trataba de divulgar entre su pueblo la idea de un Imperio moderno" (Speer 1969: 104).

Hitler recogía así todas las definiciones de lo que debe ser lo prospectivo y las hacía suyas de una manera, como poco, peculiar ${ }^{3}$.

Lo que nos dice esta definición lo tiene Hitler muy presente. A saber, un acercamiento al terreno para detectar una posible enfermedad latente, cosa que Hitler buscaba de manera insaciable e hipocondriaca, proyectando todos sus planes de futuro en lo que él diagnosticaba. Para ello realizaba un "examen del subsuelo", que en su caso significaba un hipernacionalismo, una búsqueda en las raíces del "pueblo" para utilizarlas como punto de partida. Y con todo ello realizaba la pertinente "exploración de posibilidades futuras", que plasmaba en edificios imperecederos con la ayuda de Speer.

Con estas cavilaciones de fondo, y con el proyecto en marcha del Zeppelinfeld dedicado a los grandes eventos del partido, Speer desarrolló en 1934, tal y como él reconoció bajo un título algo pretencioso, "la teoría del valor como ruina" de una construcción.

Albert Speer había visitado el enclave en el que se iba a ubicar la tribuna del Zeppelinfeld, que anteriormente había sido el hangar de los tranvías de Nüremberg: "[Entonces] pasé ante el amasijo que formaban los restos de hormigón armado del hangar tras su voladura; las barras de hierro asomaban por doquier y habían comenzado a oxidarse. Era fácil imaginar su ulterior descomposición" (Speer 1969: 104). Así concluyó que las construcciones modernas no estaban preparadas para ser ese "puente de tradición" necesario para las futuras generaciones, y que formaba además parte de los deseos de Hitler. "Resultaba inimaginable que unos escombros oxidados trasmitieran el espíritu heroico que Hitler admiraba de los monumentos del pasado".

Para ello y a partir de entonces Speer propuso a Hitler que los edificios se realizaran de tal manera que en periodos de decadencia, y tras 1000 años, siguieran siendo vistosos, como en el caso de sus modelos romanos.

Albert Speer está fundando aquí, con cierta raigambre romántica e historicista, una ontología de la decadencia, una ontología al servicio no ya del presente, sino al servicio de un

\footnotetext{
${ }^{3}$ Si volvemos a revisar el término 'prospectivo' tal y como lo analiza Fernando Ángel Moreno (2010), nos encontramos con esta cita extraída del DRAE y que reproducimos aquí: "1: exploración del subsuelo basada en el examen de los caracteres del terreno y encaminada a descubrir yacimientos minerales, petrolíferos, aguas subterráneas, etc. 2: Exploración de posibilidades futuras basadas en indicios presentes. 3: Reconocimiento general que se hace para descubrir enfermedades latentes o incipientes".
} 
plausible futuro en el que las ruinas deben ser el símbolo que permita reavivar las llamas del espíritu.

Para ilustrar mis ideas, hice dibujar una imagen romántica del aspecto que tendría la tribuna del Zeppelinfeld después de varias generaciones de descuido: cubierta de hiedra, con los pilares derruidos y los muros rotos [...] pero todavía reconocible. (Speer 1969: 106)

Esta idea, este dibujo, fue considerado una herejía en el entorno de Hitler. Y es que la posibilidad de un periodo de decadencia en el imperio de los mil años recién fundado no era concebible. "Sin embargo, a Hitler aquella reflexión le pareció evidente y lógica. Ordenó que, en lo sucesivo, las principales edificaciones de su Reich se construyeran de acuerdo con la ley de las ruinas" (Speer 1969: 106).

Algo similar dijo más tarde María Zambrano, en el de compendio textos que, en los años 50, se publicaría con el título de Islas. Ahí asevera: "Las ruinas son una categoría de la historia y hacen alusión a algo muy íntimo de nuestra vida. Son el abatimiento de esa acción que define al hombre entre todas: edificar. Edificar, haciendo historia. Es decir, una doble edificación: arquitectónica e histórica" (Zambrano 2007: 127).

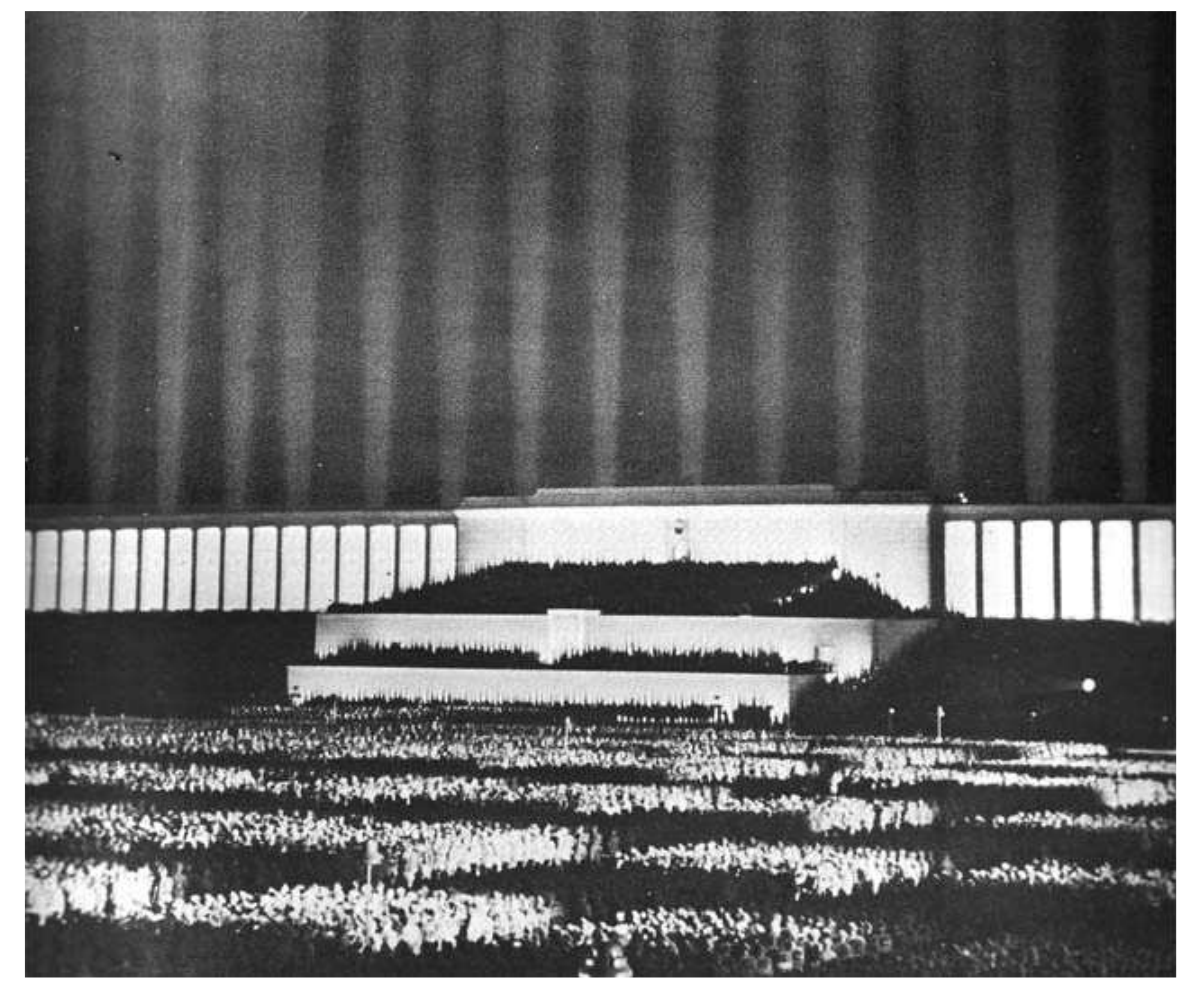

Figura 3. Catedral de luz en un congreso del partido nacional socialista en Nüremberg. 
La raigambre filosófica no deja de ser nietzscheana, pese a lo mucho que ha sido manchado el nombre de Nietzsche y su utilización en no pocas ocasiones por el nazismo; sí es cierto que el mismo Nietzsche criticó la manera de hacer historia propia de los historiadores. Una crítica al filólogo e historiador común. Él mismo dijo que la historia buena, la verdadera historia, es la que vivifica el presente.

Es el trabajo que se proponen tanto Speer como Hitler, dejar un legado arquitectónico tal que en su época sea imagen del presente esplendoroso, anuncio de la utopía, y que en un plausible futuro decadente sea la salvación del alma inmortal del Reich.

Pero la comprensión de ese futuro, que se traduce a la vez en ideales utópicos matizados por la posibilidad de la decadencia, está sentando las bases de un mundo distópico, de un futuro fracasado, en el que los románticos por venir tendrán que avivar la llama del espíritu tal y como los primeros románticos de finales del siglo XVIII buscaban en las ruinas de iglesias, en la literatura y en los parajes desolados los vestigios del espíritu idealizado del pasado. La intención de Albert Speer es ponérselo fácil al futuro "romanticismo", y a Hitler eso le parece una buena idea.

Lo interesante es que una ontología negativa como es la prospectiva puede crear normatividad en el presente, o tener como rendimiento o positividad un nuevo presente, es decir, un hablar sobre el no ser que es lo prospectivo crea una normatividad que afecta al presente, y así es exactamente como funciona la ciencia ficción en su faceta prospectiva. Ese "al fin y al cabo es literatura" es en el caso de lo prospectivo un anuncio, una llamada a una posible modulación de la realidad. La presentación del nóvum plantea diferentes resoluciones para un paradigma que siempre es posible. $Y$ esto el fascismo lo comprendió muy bien. Como vemos, esto encaja además con esa nueva significación temporal que se daba paralelamente en la filosofía.

La ontología de la ausencia se convirtió también en un refuerzo arquitectónico. La catedral de luz, usada para crear en Nüremberg ese sentimiento de comunidad, servía para, con un juego de luces, cubrir la ausencia de la noche y envolver a los allí presentes en aquel éxtasis de catastróficas consecuencias (figura 3). 


\section{Conclusiones}

En la base de todas las épocas subyace una concepción temporal que cala y hace mella en todas las producciones de su tiempo. La selección de la ciudad en los totalitarismos, aunada con la filosofía de la época y la literatura prospectiva, se torna así esencial, y revela con un mero análisis estructural interesantes datos acerca de su concepto de tiempo y las relaciones de este concepto con el funcionamiento de una sociedad.

Para acabar, una cita de las memorias se muestra especialmente reveladora para poder cerrar un artículo que baila entre dos aguas que son diferentes, pero que, por ser agua, ya son lo mismo.

Tras años de esfuerzos baldíos, me sentía lleno de ganas de trabajar; sólo tenía veintiocho años. Como Fausto, habría vendido mi alma por hacer un gran edificio. Ahora había encontrado a mi Mefistófeles. No me pareció menos absorbente que el de Goethe. (Speer 1969: 60)

Lo que hay que remarcar es que la misma ciencia ficción intenta simbolizar ese pacto, esa relación, en muchos casos cuasi simbiótica, entre lo que acaece y lo plausible. Y tanto en la arquitectura como en la ciencia ficción el pacto está conformado en torno a ese eje sociotecnológico del que es imposible escapar y que configura el propio mundo circundante y la proyección de esa entidad curiosa o ser.

\section{Bibliografía}

DERRIDA, Jacques (1968): Tiempo y presencia. Santiago de Chile: Editorial Universitaria. Versión electrónica disponible en: http://www.ddooss.org/articulos/textos/Tiempo presencia.pdf

HEIDEGGER, Martin (1927): Ser y Tiempo. Madrid: Trotta.

HELD, Klaus (2009): "Fenomenología del 'tiempo propio' en Husserl y Heidegger" [en línea]. La lámpara de Diógenes, núm. 18-19, pp. 929. En: http://www.Idiogenes.buap.mx/revistas/18/9.pdf [Consulta: septiembre de 2011].

HUSSERL, Edmund (1921): Meditaciones cartesianas. Madrid: Fondo de Cultura Económica.

MORENO, Fernando Ángel (2010): Teoría de la literatura de ciencia ficción: Poética y retórica de lo prospectivo. Vitoria: Portal Editions.

NIEL, Luis I. (2002): "El tiempo y la posibilidad de un encuentro entre Husserl y Derrida" [en línea]. Tópicos, número 10, pp. 121-136. En: http://redalyc.uaemex.mx/redalyc/pdf/288/28801007.pdf [Consulta: septiembre de 2011].

RODRÍGUEZ, Ramón (2002): Del sujeto y la verdad. Madrid: Síntesis.

SPEER, Albert (1969): Memorias. Barcelona: Acantilado

ZAMBRANO, María (2007): "Una metáfora de la esperanza: Las Ruinas", en Islas, pp. 123-128. Madrid: Verbum. 